\title{
Impact of symptoms on quality of life before and after diagnosis of coeliac disease: results from a UK population survey
}

\author{
Alastair M Gray ${ }^{*+1}$ and Irene N Papanicolas ${ }^{\dagger 2}$
}

\begin{abstract}
Background: Coeliac disease is a common chronic autoimmune disorder. Underdiagnosis is common and the quality of life impact of symptoms may be severe. We report a study of symptom duration and quality of life before and after diagnosis in a representative sample of people with diagnosed coeliac disease in the UK.

Methods: Postal questionnaire of 2000 people with diagnosed coeliac disease, requesting information on date of diagnosis, type and duration of symptoms, and quality of life before and after diagnosis using the EQ-5D instrument.

Results: The survey response rate was $40 \%$ (788/2000). Mean duration of symptoms prior to diagnosis was 13.2 years, with some evidence of shorter duration in recent years. Respondents reported a mean of 13 consultations with their GP about their symptoms prior to diagnosis. The mean utility value of pre-diagnosis quality of life was 0.56 , compared to 0.84 at time of survey, a highly statistically significant improvement of 0.27 ( $95 \%$ c.i. $0.25,0.30$ ).

Conclusions: The symptoms of undiagnosed coeliac disease are associated with a prolonged and substantial decrement to quality of life. These results strengthen the case for detailed examination of the cost-effectiveness of improved methods of detection and diagnosis, including population screening.
\end{abstract}

\section{Background}

Coeliac disease is a common chronic autoimmune disorder with a prevalence amongst adults and children approaching $1 \%$ of the population in international studies $[1,2]$. Underdiagnosis is common [3] and some studies have reported frequent presentation with symptoms over many years prior to diagnosis [4], although rates of diagnosis are increasing in many countries [5]. Once diagnosed, adherence to treatment involving the lifelong elimination of wheat, rye and barley from the diet results in significant clinical improvement for most patients. A small number of studies have examined the quality of life of coeliac patients, but these have typically focussed on the quality of life of patients after diagnosis in relation to the general population, and in particular on the impact of a gluten free diet, and have relied on small samples and instruments that do not facilitate comparison [6-8]. Here

\footnotetext{
* Correspondence: alastair.gray@dphpc.ox.ac.uk

1 Health Economics Research Centre, Department of Public Health, University of Oxford, Old Road Campus, Oxford, UK

+ Contributed equally

Full list of author information is available at the end of the article
}

we report on a survey of people with coeliac disease, in which information was collected on the duration and types of symptoms experienced prior to diagnosis, the number of consultations about these symptoms prior to diagnosis, and quality of life before and after diagnosis using for the first time in this population the EQ-5D instrument, a generic utility-based instrument that is widely used in surveys and favoured in technology assessment as it facilitates comparison across disease areas and the general population $[9,10]$. We focus on comparisons before and after diagnosis, but also examine whether the introduction of serological testing, approximately between 1993 and 2000 [5], altered characteristics at diagnosis.

\section{Methods}

A representative sample of 2,000 individuals was drawn from the membership list of Coeliac UK, the leading charity working for people with coeliac disease and dermatitis herpetiformis (DH) in the UK with a total membership of 70,000 or $56 \%$ of the estimated 125,000 people

( 2010 Gray and Papanicolas; licensee BioMed Central Ltd. This is an Open Access article distributed under the terms of the Creative BioMed Central Commons Attribution License (http://creativecommons.org/licenses/by/2.0), which permits unrestricted use, distribution, and reproduction in any medium, provided the original work is properly cited. 
with a clinical diagnosis of coeliac disease in the UK as of October 2007. A short questionnaire was designed, containing questions on demographic characteristics, time since diagnosis, type and duration of symptoms prior to diagnosis, and quality of life before and after diagnosis, using the EQ-5D questionnaire. Other data collected in the questionnaire, for example on impact on daily activities and out-of-pocket costs associated with coeliac disease before and after diagnosis, are not reported here. The symptom lists were devised based on existing literature, and revised following piloting of the questionnaire with a local Coeliac UK members group. A copy of the questionnaire accompanies this article [Additional file 1].

Where members were known to be under 18 years of age, the parent or guardian was asked to complete the questionnaire on behalf of or with the member. The questionnaire was publicised in the Coeliac UK Newsletter sent to all members, and mailed with a covering letter and prepaid return envelope to the sample. The sample approached was stratified by each country of the UK, postal town or county, and date of joining Coeliac UK. Reminders to return the questionnaire were also publicised in Coeliac UK newsletters. The survey was conducted in 2007.

Data were entered onto a database, and a $10 \%$ sample was double-entered to check whether any coding inconsistencies were concentrated in particular parts of the questionnaire. These were then resolved by discussion and re-examination of data.

No imputation was conducted to deal with missing data, and results are presented using complete cases for the relevant question or combination of questions. Ttests were performed to assess whether missing cases were significantly different from compete cases.

Responses to the EQ-5D questions were given a quality of life valuation using the UK population tariff [11], and were compared with population norms derived from a national survey [12], having age- and sex-standardised to the survey population. Proportions reporting no problems before diagnosis and now in response to each EQ$5 \mathrm{D}$ question were compared using McNemar's chisquared test. Results were analysed in SPSS version $15{ }^{\circ}$

\section{Data}

788 of 2000 questionnaires were returned, a response rate of just under $40 \%$. The age and sex distribution of respondents were compared with the Coeliac UK general membership and no statistically significant differences were observed. The level of non-response varied from 2/788 $(<0.5 \%)$ for presence of symptoms to $133 / 788$ (17\%) for number of GP consultations prior to diagnosis.

\section{Results}

93\% of respondents $(728 / 783)$ were the only member of their household with coeliac disease, with $7 \%$ sharing their household with at least one other person diagnosed with coeliac disease.

$28 \%$ of respondents (220/777) were male and $72 \%$ (557/ 777) female. The mean age (SD) of respondents was 52 (18) years, with a range from 2 to $89.12 \%(97 / 777)$ of respondents were aged less than 18 years, and 10\% (80/ 777 ) were aged 65 or over. On average respondents were aged 41.3 years (SD 19) when they were diagnosed with CD. The mean age at diagnosis was 39 (SD 18) for those diagnosed before the year 2000, compared to 44 for those diagnosed after 2000, a significant difference of 5 years (95\% ci 2.7 to 8.0 ).

Table 1 reports the frequency and duration of reported symptoms prior to diagnosis. The most common symptoms were abdominal pain/bloating (71\%), diarrhoea (70\%), anaemia (65\%), chronic fatigue (62\%), and weight loss (61\%). $78 \%$ of respondents $(605 / 777)$ reported at least 4 symptoms, and only $1 \%(6 / 777)$ of respondents reported no symptoms prior to diagnosis.

The mean duration of specific symptoms ranged from 12.6 years for constipation to 5.5 years for weight loss. The average duration of any symptom before diagnosis across the whole sample was 13.2 (SD 16.0) years. The duration of symptoms in those diagnosed before and after the year 2000 was 14.5 and 12.0 years respectively, a significant difference of 2.5 years (95\% CI 0.2. 4.9).

655 respondents $(83 \%)$ provided information about the number of times they had seen their GP about their symptoms during the period prior to diagnosis, and Table 2 reports details. On average, respondents consulted their GP 13.0 times about their symptoms. This was related to duration of symptoms: those whose symptoms had lasted for less than 1 year before diagnosis consulted GPs on average 4.5 times for symptom related consultations, whereas those whose symptoms had lasted for 20 or more years had consulted their GP on average 27.7 times for symptom related consultations. The average number of pre-diagnosis visits to GPs about symptoms was 7.0 amongst those diagnosed after the year 2000 compared to 17.4 amongst those diagnosed before 2000 , a mean difference of 10.4 visits (95\% CI 2.3, 18.5). Adjusted for age of respondent and duration of symptoms, this difference remained a statistically significant 11.4 visits (95\% CI 1.9, 20.8).

Table 3 reports the number and percent of respondents at different levels of each of the 5 questions comprising the EQ-5D, before and after diagnosis, and the corresponding percentages at each level in the general population of England. Results are shown for the 697 of 788 respondents (88\%) completing EQ-5D questionnaires for both their pre-diagnosis and their current health state.

In all five dimensions of the EQ-5D, the proportion of respondents reporting no problems was significantly higher at the time of the survey compared to before diagnosis: this was particularly pronounced in the pain 
Table 1: Frequency and duration of symptoms prior to diagnosis of coeliac disease.

\begin{tabular}{|c|c|c|c|c|c|}
\hline \multirow[t]{2}{*}{ Symptom: } & \multicolumn{3}{|c|}{$\begin{array}{l}\text { Number (\%) reporting symptoms } \\
\text { (of } 777 \text { respondents) }\end{array}$} & \multicolumn{2}{|c|}{ Duration of symptoms (years) } \\
\hline & Number & $\%$ & $(95 \% \mathrm{Cl})$ & Mean & $(95 \% \mathrm{Cl})$ \\
\hline Any symptom & 771 & 99 & $(98,100)$ & 13.2 & $(12.1,14.4)$ \\
\hline Abdominal pain/bloating & 556 & 71 & $(67,74)$ & 7.9 & $(7.0,8.7)$ \\
\hline Diarrhoea & 553 & 70 & $(67,73)$ & 6.9 & $(6.1,7.8)$ \\
\hline Anaemia & 509 & 65 & $(61,680$ & 11.5 & $(10.5,12.6)$ \\
\hline Chronic fatigue & 488 & 62 & $(59,650$ & 7.1 & $(6.3,7.9)$ \\
\hline Weight loss & 479 & 61 & $(57,640$ & 5.5 & $(4.7,6.2)$ \\
\hline Flatulence & 368 & 47 & $(43,50)$ & 9.5 & $(8.6,10.4)$ \\
\hline Mouth ulcer & 236 & 30 & $(27,33)$ & 11.2 & $(10.1,12.3)$ \\
\hline Headache & 232 & 30 & $(26,33)$ & 10.3 & $(9.3,11.3)$ \\
\hline Joint pain & 220 & 28 & $(25,31)$ & 8.2 & $(7.4,9.0)$ \\
\hline Skin rash & 208 & 26 & $(23,30)$ & 9.9 & $(8.9,10.9)$ \\
\hline Constipation & 207 & 26 & $(23,29)$ & 12.6 & $(11.5,13.6)$ \\
\hline Depression & 185 & 24 & $(21,27)$ & 9.2 & $(8.3,10.1)$ \\
\hline Other symptoms & 163 & 21 & $(18,24)$ & 5.4 & $(4.8,6.1)$ \\
\hline Osteoporosis & 91 & 12 & $(10,14)$ & 7.7 & $(6.7,8.6)$ \\
\hline Ataxia & 39 & 5 & $(3,7)$ & 6.1 & $(5.2,6.9)$ \\
\hline No symptoms & 6 & 1 & $(0,2)$ & & \\
\hline
\end{tabular}

dimension, with $60 \%$ reporting themselves to have no problems at the time of the survey, compared to only $22 \%$ prior to diagnosis of coeliac disease. The distribution of responses from a large general population survey in England, age- and sex-standardised to the survey respondent population, is also shown in Table 3: across all five health dimensions the proportion of respondents reporting no problems before diagnosis was lower than in the general population, but at time of survey was similar to or higher than in the general population.

Placing valuations on these EQ-5D health states using the British "tariff"11 (Table 4), the mean quality of life before diagnosis was 0.56 , (where $0=$ death and $1=$ full health), and 0.84 at the time of the survey, indicating a highly statistically significant improvement of 0.27 (95\% c.i. $0.25,0.30)$. By comparison, the average quality of life in the general population has been reported as 0.82 when age-sex-standardised to age of respondents at time of survey response, or 0.85 when age-standardised to age of respondents at age at diagnosis [12].

On the Visual Analogue Scale, respondents rated their health at $47 \%$ before diagnosis ( $0=$ worst imaginable state, 100 = best imaginable state), and at 79\% now, a highly significant improvement of 32 (95\% C.I. 30, 35) percentage points.

Table 2: Mean number of GP consultations pre-diagnosis about symptoms, by duration of symptoms.

\begin{tabular}{lccc}
\hline \multicolumn{4}{c}{ Number of consultations } \\
\hline Duration of all symptoms in years: & Mean & $\mathbf{N}$ & $\mathbf{9 5 \%} \mathbf{C l}$ \\
$>1$ & 4.5 & 106 & $(3.5,5.5)$ \\
$1-5$ & 9.2 & 170 & $(4.1,14.3)$ \\
$5-10$ & 8.4 & 79 & $(6.1,10.7)$ \\
$10-20$ & 8.9 & 95 & $(6.5,11.4)$ \\
$>20$ & 27.7 & 155 & $(11.4,44.1)$ \\
Total & 13.0 & 605 & $(8.5,17.5)$ \\
\hline
\end{tabular}


Table 3: Respondents' self-reported health on EQ-5D before diagnosis of coeliac disease (retrospective) and now: number and percent by level of response, and UK population norms (percent)*1.

\begin{tabular}{|c|c|c|c|c|c|c|}
\hline \multirow[t]{2}{*}{ EQ-5D question: } & \multicolumn{2}{|c|}{$\begin{array}{c}\text { Level 1: } \\
\text { No problems }\end{array}$} & \multicolumn{2}{|c|}{$\begin{array}{c}\text { Level 2: } \\
\text { Some problems }\end{array}$} & \multicolumn{2}{|c|}{$\begin{array}{c}\text { Level 3: } \\
\text { Severe problems }\end{array}$} \\
\hline & $\mathbf{N}$ & $\%$ & $\mathbf{N}$ & $\%$ & $\mathbf{N}$ & $\%$ \\
\hline \multicolumn{7}{|l|}{ Mobility: } \\
\hline before diagnosis & 524 & 75 & 159 & 23 & 14 & 2 \\
\hline Now & 602 & $86^{*}$ & 93 & 13 & 2 & 0 \\
\hline UK population norm & & 78 & & 22 & & 0 \\
\hline \multicolumn{7}{|l|}{ Self-care: } \\
\hline before diagnosis & 648 & 93 & 35 & 5 & 14 & 2 \\
\hline Now & 673 & $97^{*}$ & 18 & 3 & 6 & 1 \\
\hline UK population norm & & 93 & & 6 & & 0 \\
\hline \multicolumn{7}{|l|}{ Usual activities: } \\
\hline before diagnosis & 403 & 58 & 249 & 36 & 45 & 6 \\
\hline Now & 574 & $82^{*}$ & 116 & 17 & 7 & 1 \\
\hline UK population norm & & 78 & & 19 & & 3 \\
\hline \multicolumn{7}{|l|}{ Pain: } \\
\hline before diagnosis & 153 & 22 & 349 & 50 & 195 & 28 \\
\hline Now & 416 & $60^{*}$ & 252 & 36 & 29 & 4 \\
\hline UK population norm & & 58 & & 37 & & 4 \\
\hline \multicolumn{7}{|l|}{ Anxiety/depression: } \\
\hline before diagnosis & 351 & 50 & 259 & 37 & 87 & 12 \\
\hline Now & 518 & $74^{*}$ & 163 & 23 & 16 & 2 \\
\hline UK population norm & & 75 & & 23 & & 2 \\
\hline
\end{tabular}

*Proportion reporting no problem significantly different now compared to before diagnosis (McNemar-Bowker Chi-square test, $\mathrm{p}<0.01$ )

1 UK population norms from Health Survey for England 1996, standardised to age distribution of Coeliac UK survey respondents now.

There was no clear evidence that the levels of health reported by respondents before and after diagnosis was related to duration of symptoms. Respondents who were diagnosed prior to 2000 had a mean EQ-5D tariff of 0.55 , compared with 0.58 amongst those diagnosed after 2000, a small but not statistically significant difference of 0.03 (95\% C.I. -0.02, 0.08). Similarly, the VAS was slightly but not significantly higher at diagnosis amongst those diagnosed after 2000 (49\%) compared with those diagnosed before 200 (46\%) (mean difference 3, 95\% C.I. -1, 6).

Figure 1 shows levels of health reported by respondents, by age group, before diagnosis and at the time of the survey. Levels of health were clearly related to age before diagnosis, rising from 0.52 (95\% C.I. 0.45, 0.58) amongst those aged 18-34 when diagnosed to 0.71 (95\% C.I. $0.65,0.78$ ) amongst those aged 65 and over at diagnosis. No such differences between age groups were evident in reported quality of life at time of survey. However, all age groups reported a significant improvement in quality of life at the time of the survey compared to the period prior to diagnosis.

\section{Discussion}

In this study we have shown that the quality of life of people with undiagnosed symptomatic coeliac disease is substantially reduced compared to the general population, and increases markedly after diagnosis. The difference ( 0.56 prior to diagnosis (where $0=$ death and $1=$ full health) to 0.84 at the time of the survey), is quantitatively similar to the quality of life impact of severe events such as stroke [13].

Our study found a mean duration of symptoms of 13.2 years; although there was some evidence that this had fallen since the widespread adoption of serological testing in the 1990s, the mean duration of symptoms of those diagnosed after the year 2000 was still 12 years. These durations are similar to the 11 years with symptoms prior to diagnosis reported in a large American study, which also showed some evidence of reduced duration of symp- 
Table 4: Respondents' self-reported health on EQ-5D before diagnosis of coeliac disease (retrospective) and now: mean score on Visual Analogue Scale and mean tariff-based valuation of health state, and UK population norm ${ }^{1}$.

\begin{tabular}{|c|c|c|}
\hline & Mean & $95 \% \mathrm{Cl}$ \\
\hline \multicolumn{3}{|l|}{ EQ-5D tariff: } \\
\hline pre-diagnosis & 0.56 & $(0.54,0.59)$ \\
\hline time of survey & 0.84 & $(0.82,0.85)$ \\
\hline change & 0.27 & $(0.25,0.30)$ \\
\hline \multicolumn{3}{|c|}{$\begin{array}{l}\text { UK population norm, standardised to age } \\
\text { distribution of respondents at: }\end{array}$} \\
\hline time of survey & 0.82 & $(0.81,0.83)$ \\
\hline time of diagnosis & 0.85 & $(0.84,0.86)$ \\
\hline \multicolumn{3}{|l|}{ Visual Analogue Scale: } \\
\hline pre-diagnosis & $47 \%$ & $(45,49)$ \\
\hline time of survey & $79 \%$ & $(78,80)$ \\
\hline change & $32 \%$ & $(30,35)$ \\
\hline
\end{tabular}

1 UK population norms from Health Survey for England 1996, standardised to age distribution of Coeliac UK survey respondents now.

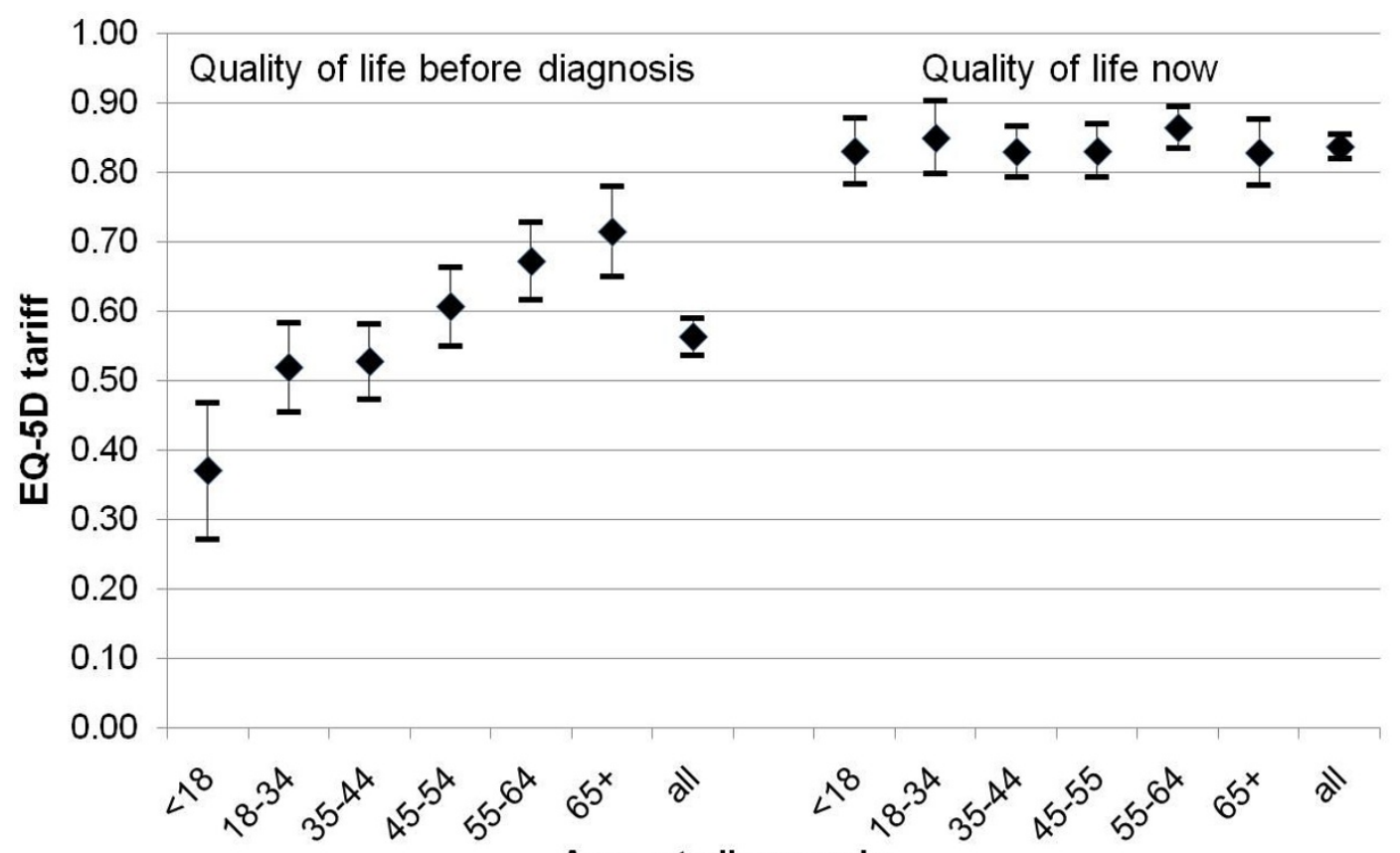

Age at diagnosis

Figure 1 Respondents' self-reported health on EQ-5D before diagnosis of coeliac disease (retrospective) and now: mean tariff-based valuation of health state, by age at diagnosis. 
toms following the introduction of serological testing [14].

Previous studies of quality of life associated with coeliac disease have not focused on differences before and after diagnosis, and have not used the EQ-5D. One advantage of the EQ-5D is that it is a widely used generic quality of life instrument that permits comparison across many different disease areas, and is therefore particularly useful in assessing the comparative cost-effectiveness of a wide range of different interventions: for this reason the EQ$5 \mathrm{D}$ is the only quality of life instrument specifically recommended for calculating quality adjusted life years by the National Institute of Health and Clinical Excellence in its recommended methods for technology appraisal [10]. The EQ-5D derived estimates of utility before and after diagnosis reported here, and the estimated duration of symptoms prior to diagnosis, may be helpful in assessing the cost-effectiveness of improved methods of screening and detection; such studies to date have typically concentrated on cost per case detected [15], often in population sub-groups [16] or have specifically excluded quality of life due to the prior lack of reliable estimates [17]. A systematic review undertaken to inform the cost-effectiveness modelling that formed part of the NICE Guidelines on celiac disease published in 2009 was unable to find any utility estimates in the literature at that time [18].

Our estimates of quality of life prior to diagnosis of coeliac disease are based on retrospective assessment; such methods are unavoidable in the absence of very large long-term prospective studies, and have been used before with different instruments and in different disease areas $[19,20]$, but it is not known whether the results obtained would be comparable with those derived from prospective studies, and there is a lack of information on this with the EQ-5D or indeed other instruments. Similarly, although there is no evidence that the respondents to this survey were different to non-respondents, it is possible that the population from which the sample was drawn members of Coeliac UK, stratified by area and duration of membership - are in some way unrepresentative of the entire population of those with diagnosed coeliac disease. However, given the magnitude of the quality of life differences reported in this study, and given that the charity has $56 \%$ of all diagnosed patients enrolled in its membership, it seems unlikely that any recall or sampling bias could seriously alter the results.

\section{Conclusions}

The symptoms of undiagnosed coeliac disease are associated with a prolonged and substantial decrement to quality of life. In light of these results, the case for detailed examination of the cost-effectiveness of improved methods of detection and diagnosis, including population screening, seems compelling.

\section{Additional material}

Additional file 1 A copy of the questionnaire used for the survey. This is a nine-page questionnaire in PDF format. Some sections relate the quality of life survey reported here, and some to other data collected.

\section{Competing interests}

The authors declare that they have no competing interests.

\section{Authors' contributions}

AMG designed the study, participated in the data analysis and drafted the manuscript. ING participated in the design of the survey questionnaire, transcribed, coded and analysed the responses and helped to draft the manuscript. Both authors read and approved the final manuscript.

\section{Acknowledgements}

This research was funded with the assistance of a research grant to the University of Oxford from Coeliac UK, who also kindly provided access to their members' list to draw the survey sample. We are grateful to Coeliac UK for this support. The funders had no role in the design, analysis or interpretation of this study, or in the decision to submit for publication. We are grateful to Coeliac UK, particularly Sarah Sleet and Norma McGough, for encouragement and advice, and to everyone who responded to the survey.

\section{Author Details}

${ }^{1}$ Health Economics Research Centre, Department of Public Health, University of Oxford, Old Road Campus, Oxford, UK and 2LSE Health, London School of Economics and Political Science, Houghton Street, London, UK

Received: 8 January 2010 Accepted: 27 April 2010

Published: 27 April 2010

\section{References}

1. West J, Logan RFA, Hill PG, et al:: Seroprevalence, correlates, and characteristics of undetected coeliac disease in England. Gut 2003, 52(7):960-965

2. Bingley PJ, Williams AJK, Norcross AJ, et al.: Undiagnosed coeliac disease at age seven: population based prospective birth cohort study. BrMed J 2004, 328(7435):322-323.

3. Hin H, Bird G, Fisher P, Mahy N, Jewell D: Coeliac disease in primary care: case finding study. BrMed J 1999, 318(7177):164-167.

4. Dickey W, McConnell JB: How many hospital visits does it take before celiac sprue is diagnosed? Journal of Clinical Gastroenterology 1996, 23(1):21-23.

5. Green PHR, Jabri B: Coeliac disease. Lancet 2003, 362(9381):383-391.

6. Zarkadas M, Cranney A, Case S, et al:: The impact of a gluten-free diet on adults with coeliac disease: results of a national survey. Journal of Human Nutrition and Dietetics 2006, 19(1):41-49.

7. Hallert C, Lohiniemi S: Quality of life of celiac patients living on a glutenfree diet. Nutrition 1999, 15(10):795-797.

8. Peraaho M, Kaukinen K, Mustalahti K, et al.: Effect of an oats-containing gluten-free diet on symptoms and quality of life in coeliac disease. A randomized study. Scandinavian Journal of Gastroenterology 2004, 39(1):27-31.

9. EuroQol Group: EuroQol - a new facility for the measurement of healthrelated quality of life. Health Policy 1990, 16:199-208.

10. NICE: Guide to the methods of technology appraisal London: National Institute for Clinical Excellence; 2008.

11. Dolan P, Gudex C, Kind P, Williams A: The time trade-off method: results from a general population study. Health Econ 1996, 5(2):141-154.

12. Health Survey: Health Survey for England 1996 London: The Stationery Office; 1998.

13. Clarke $P$, Gray $A$, Holman R: Estimating utility values for health states of type 2 diabetic patients using the EQ-5D (UKPDS 62). Med Decis Making 2002, 22(4):340-349

14. Green PHR, Stavropoulos SN, Panagi SG, et al:: Characteristics of adult celiac disease in the USA: results of a national survey. Am J Gastroentero/ 2001, 96(1):126-131. 
15. Harewood GC, Murray JA: Diagnostic approach to a patient with suspected celiac disease - A cost analysis. Digestive Diseases and Sciences 2001, 46(11):2510-2514.

16. Holmes GKT: Screening for coeliac disease in type 1 diabetes. Archives of Disease in Childhood 2002, 87(6):495-499.

17. Shamir R, Hernell O, Leshno M: Cost-effectiveness analysis of screening for Celiac disease in the adult population. Med Decis Making 2006, 26(3):282-293

18. NICE: Coeliac Disease: Recognition and assessment of Coeliac Disease. NICE Clinical Guideline 86 London: National Institute for Clinical Excellence; 2009

19. Legler J, Potosky AL, Gilliland FD, Eley JW, Stanford JL: Validation study of retrospective recall of disease-targeted function - Results from the prostate cancer outcomes study. Med Care 2000, 38(8):847-857.

20. Watson WL, Ozanne-Smith J, Richardson J: Retrospective baseline measurement of self-reported health status and health-related quality of life versus population norms in the evaluation of post-injury losses. Injury Prevention 2007, 13(1):45-50.

\section{Pre-publication history}

The pre-publication history for this paper can be accessed here: http://www.biomedcentral.com/1472-6963/10/105/prepub

doi: $10.1186 / 1472-6963-10-105$

Cite this article as: Gray and Papanicolas, Impact of symptoms on quality of life before and after diagnosis of coeliac disease: results from a UK population survey BMC Health Services Research 2010, 10:105

Submit your next manuscript to BioMed Central and take full advantage of:

- Convenient online submission

- Thorough peer review

- No space constraints or color figure charges

- Immediate publication on acceptance

- Inclusion in PubMed, CAS, Scopus and Google Scholar

- Research which is freely available for redistribution

Submit your manuscript at www.biomedcentral.com/submit
C) Biomed Central 